Obere Extremität 2017 • 12:38-45 DOI 10.1007/s11678-016-0386-9

Received: 5 September 2016

Accepted: 4 November 2016

Published online: 1 December 2016

C Springer Medizin Verlag Berlin 2016

CrossMark

\author{
Malte Holschen ${ }^{1}(\mathbb{D}) \cdot$ Florian Brand $^{2}$. Jens D. Agneskirchner \\ ${ }^{1}$ Raphaelsklinik Münster, Münster, Germany \\ ${ }^{2}$ Medizinische Hochschule Hannover, Hannover, Germany \\ ${ }^{3}$ Klinik für Gelenkchirurgie und Orthopädie (GOH), Hannover, Germany
}

\title{
Subacromial spacer implantation for massive rotator cuff tears
}

\section{Clinical outcome of arthroscopically treated patients}

There are several treatment options for massive rotator cuff tears (MRCT). Especially in elderly patients, conservative treatment is often favored because of the risks posed by anesthesia and surgery.

If massive tears have resulted in a cuff tear arthropathy with pseudoparalysis of the affected shoulder, a reverse total shoulder arthroplasty is often the only remaining treatment option. Younger patients with reduced active external rotation and abduction because of massive posterosuperior cuff tears and an intact subscapularis tendon can benefit from a latissimus dorsi transfer [3].

Minimally invasive treatment options are chosen in cases of a painful MRCT in absence of a severely impaired function. Patients who cannot or do not want to undergo extended open surgery may benefit from conventional arthroscopic treatment with a combination of biceps tenotomy, cuff debridement, synovectomy, bursectomy, and partial repair or margin-convergence stitches. Of course a complete repair should always be performed, if possible. But the retear rate is high [7] and failures with persistent pain exist.

The InSpace Balloon (ISB ${ }^{\circledR}$; Orthospace, Israel) is a new arthroscopic treatment option that is used "on top" of conventional arthroscopic treatments for MRCT. It consists of poly-L-lactide (PLLA), which is a biodegradable synthetic material and is inflated with a physiologic saline solution. PLLA is not known to have toxic or tumorigenic properties [11]. The inflated spacer reduces subacromial friction and extends the space between the humeral head and acromion and coracoacromial arch [12]. It cannot reduce a static superior or anterosuperior migration of the humeral head but it helps to keep the humeral head centered during dynamic movements. After cuff repair or partial repair the balloon reduces friction forces and maintains the integrity of the repaired cuff [1]. The balloon deflates after 10 weeks and the PLLA is resorbed totally after 15 months.

The ISB has been certified for the treatment of MRCT in Europe since 2010. While the number of implanted balloons is rising, there is still a lack of data about the clinical outcome. This study investigates the clinical results of patients treated with conventional arthroscopic options for MRCT and compares them with those of patients who received an ISB "on top" of conventional arthroscopic treatment. The hypothesis was that even a poor preoperative shoulder function can be improved by both conventional arthroscopic techniques and the implantation of an ISB.

\section{Materials and methods}

This retrospective case-control study comprised 23 Patients with an MRCT. Patients were selected from the institutional database. The indication for surgery was a painful loss of shoulder function in the absence of osteoarthri- tis, cranial migration of the humeral head greater than type II according to Hamada's classification, and cuff tear arthropathy.

In group $A, 11$ patients (female, $n=$ 5 , male, $n=6$; mean age $=64.6$ years) were treated by a single surgeon under general anesthesia in beach-chair position with debridement of the rotator cuff, synovectomy, bursectomy, biceps tenotomy/tenodesis, and partial reconstruction of the rotator cuff, if possible. Partial reconstruction consisted of margin-convergence stitches and/or medialized cuff repair with suture anchors.

Group B comprised 12 patients (female, $n=6$, male, $n=6$; mean age $=$ 62.4 years) who received an ISB "on top" of the debridement or partial reconstruction. The size of the ISB was determined according to the intraoperative measurement of the distance between the glenoid rim and the most lateral aspect of the major tubercle. A large size was implanted seven times while a medium size was implanted five times. The small size was not utilized. After the insertion of the ISB under arthroscopic visualization through a lateral portal, it was insufflated with a physiologic saline solution. The insufflated volume corresponded to the manufacturer's recommendations.

Two patients were excluded from the study because their status had been converted to a reverse total shoulder arthroplasty before follow-up. One of these patients had been treated with an ISB 
Hier steht eine Anzeige.

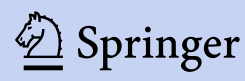




\section{Original contribution}

Table 1 Tear patterns and techniques of partial reconstruction and treatment of the long head of the biceps

\begin{tabular}{l|ll} 
& Group A $(\boldsymbol{n}=11)$ & Group B $(\boldsymbol{n}=12)$ \\
\hline Subscapularis (Lafosse) & $\begin{array}{l}5(n=1) ; 1(n=4) ; \text { intact } \\
(n=6)\end{array}$ & $\begin{array}{l}5(n=3) ; 2(n=2) ; 1(n=2) ; \text { intact } \\
(n=5)\end{array}$ \\
\hline $\begin{array}{l}\text { Long head of biceps } \\
\text { Supraspinatus (Patte) }\end{array}$ & $3(n=11)$ & $\begin{array}{l}\text { Torn }(n=7) ; \text { partial tear }(n=5) \\
3(n=12)\end{array}$ \\
Infraspinatus (Patte) & $3(n=10) ; 2(n=1)$ & $3(n=10) ; 2(n=2)$ \\
\hline Teres minor & Intact $(n=11)$ & Intact $(n=12)$ \\
\hline Biceps tenotomy & $n=4$ & $n=5$ \\
\hline Biceps tenodesis & $n=3$ & $n=0$ \\
\hline Partial repair subscapularis & $n=0$ & $n=2$ \\
\hline Partial repair supraspinatus & $n=1$ & $n=0$ \\
Partial repair Infraspinatus & $n=4$ & $n=2$ \\
\hline Margin convergence & $n=3$ & $n=1$
\end{tabular}

Table 2 Answers to questions on a four-point Likert scale ${ }^{a}$ with standard deviation (SD) of patients treated conventionally (group A) and patients who received an additional InSpace Balloon (group B) Question Answers and SD on a four-point Likert scale

\begin{tabular}{|l|l|l|} 
& Group A & Group B \\
\hline I would not undergo this type of surgery again & $1.1(0.3)$ & $1.7(1.2)$ \\
\hline I was spared from a more invasive operation & $3.7(0.9)$ & $3.6(0.9)$ \\
\hline My pain level was reduced & $3.4(1)$ & $3.3(1)$ \\
\hline I am satisfied with my clinical result & $3.6(1)$ & $3.7(0.7)$ \\
\hline${ }^{\mathrm{a}}$ 1 I disagree, 2 I rather disagree, 3 I rather agree, 4 I agree & \\
\hline
\end{tabular}

while the other had been treated conventionally.

Preoperative shoulder function was evaluated using the American Shoulder and Elbow Surgeons (ASES) and the Constant scores. For follow-up, the ASES and Constant scores were assessed. The outcome of patients who underwent conventional arthroscopic techniques (group A) was evaluated after a mean of 30.6 months. Patients treated with a supplementary ISB (group B) underwent two postoperative evaluations. The first was carried out after a mean of 11.4 months and the second after 22.3 months. The shorter final follow-up of patients treated with an ISB occurred because the ISB had not been available earlier for treatments of MRCT in our institution.

Additionally, all patients filled out a questionnaire about their subjective satisfaction based on a Likert scale. The Medical University of Hannover, Germany, provided ethical approval.
Data were analyzed with SPSS statistics (IBM, version 22.0). Paired samples were compared using Student's $t$ test for paired samples in cases of normal distribution and with the Wilcoxon test in other cases.

\section{Results}

The tear patterns and techniques of partial reconstruction for the two groups are described in 0 Table 1. An intraoperative example of a partial reconstruction in combination with an ISB is presented in - Fig. 1a-c.

Preoperative shoulder function was lower in patients treated with an ISB according to the ASES score (group A: 59.1 and group $B: 31.5$ ) and the Constant score (group A: 60.7 and group B: 36.8 ).

At follow-up, both groups had an improved shoulder function. Conventionally treated patients gained a mean of 29.5 points in the ASES score $(p<0.001)$ and a mean of 16.9 points in the Constant score $(p<0.001)$. Patients treated with an ISB had a higher absolute improvement in ASES score (54.2 points; $p<$ $0.001)$ and Constant score (32.7 points; $p<0.001)$. The absolute improvement of clinical scores for both groups is illustrated in $\square$ Fig. 2. Two patients of group B had a pseudoparalytic shoulder preoperatively (Constant score: 18 and 26). Postoperatively their Constant score had improved little (30 and 34, respectively).

The mean ASES score at follow-up was 88.6 in group A and 85.7 in group B. The mean Constant score was 77.6 in group A and 69.5 in group B. Pre- and postoperative assessment of the ASES and Constant scores is summarized in $\bullet$ Fig. 3.

The additional investigation after a mean of 11.4 months in group B showed a further improvement of the clinical results until the final assessment after 22.3 months (• Fig. 4).

On a four-point Likert scale patients of both groups were satisfied with their clinical outcome at follow-up (group A: 3.6 and group B:3.7) and reported pain relief (group A: 3.5 and group B: 3.3 ). They also believed that more invasive treatment options had been avoided by their individual arthroscopic treatment (group A: 3.7 and group B: 3.6; see - Table 2).

One patient who reported an increasingly painful shoulder after 12 months was examined with magnetic resonance imaging (MRI). Besides the retracted rotator cuff tear, MRI showed remnants of the deflated ISB, which had transformed into scar tissue in the subacromial space (- Fig. 5). The patient was treated conservatively.

\section{Discussion}

To our knowledge, this is the first study focusing on the clinical outcome of patients with MRCT who were treated arthroscopically with or without an additional ISB.

The use of an ISB provided improved shoulder function at follow-up. But conventional arthroscopic treatment options also lead to improved shoulder function. Patients treated with an ISB had a higher absolute improvement of clinical scores. This finding occurred because of a lower preoperative shoulder function. A presumable reason for the lower preoperative 
Obere Extremität 2017 · 12:38-45 DOI 10.1007/s11678-016-0386-9

(c) Springer Medizin Verlag Berlin 2016

M. Holschen · F. Brand · J. D. Agneskirchner

\section{Subacromial spacer implantation for massive rotator cuff tears. Clinical outcome of arthroscopically treated patients}

\section{Abstract}

Background. Massive rotator cuff tears (MRCT) can be treated arthroscopically by partial reconstruction, tenotomy/tenodesis of the long head of the biceps, and debridement. A new treatment option is the additional implantation of a biodegradable spacer (InSpace Balloon ${ }^{\circledR}$; ISB) into the subacromial space, which reduces subacromial shear forces to keep the humeral head centered in the glenoid. The aim of this study is to investigate the clinical outcome of patients with MRCT who were treated arthroscopically with or without an additional ISB.

Methods. The clinical outcome of patients treated with conventional arthroscopic techniques ( $n=11$, group A, partial repair, biceps tenotomy, and debridement) and that of patients treated with a supplementary ISB ( $n=12$, group B) was retrospectively analyzed. Preoperatively and postoperatively, shoulder function was assessed with the Constant and American Shoulder and Elbow Surgeons (ASES) scores. At follow-up after a mean of 22 months, patients filled out a questionnaire about their subjective satisfaction. Results. Preoperative shoulder function was lower in patients treated with an ISB (ASES score: group A, 59.1; group B, 31.5; Constant score: group $A, 60.7$; group $B, 36.8$ ). At followup, both groups had improved shoulder function (Constant score: group A, 60.7-77.6; $p<0.001$; group $\mathrm{B}, 36.8-69.5 ; p<0.001$; ASES score: group $\mathrm{A}, 59.1-88.6 ; p<0.001$; group $\mathrm{B}$, $31.5-85.7 ; p<0.001)$. Patients in both groups were subjectively satisfied with their outcome. Conclusion. The ISB is a feasible treatment option for MRCT, providing subjective pain relief and improved shoulder function. Further studies with larger patient collectives and longer follow-up are needed to confirm whether it is a safe and cost-effective treatment.

Keywords

Acromion · Shoulder · Cuff, rotator .

Debridement $\cdot$ Arthroscopic surgery

\section{Implantation eines subakromialen Platzhalters bei Rotatorenmanschettenmassenruptur. Klinisches Ergebnis arthroskopisch versorgter Patienten}

\section{Zusammenfassung}

Hintergrund. Rotatorenmanschettenmassenrupturen (MRCT) können arthroskopisch durch Partialrekonstruktion, Bizepssehnentenodeseoder -tenotomie und ein Débridement therapiert werden. Eine neue Behandlungsform stellt die zusätzliche Implantation eines resorbierbaren Platzhalters (InSpace Balloon ${ }^{\circledR}$, ISB) in den Subakromialraum dar. Dieser führt zur Rezentrierung des Humeruskopfes und zur Reduktion subakromialer Scherkräfte. Ziel dieser Studie ist die Evaluation der klinischen Ergebnisse arthroskopisch therapierter Patienten mit MRCT mit oder ohne zusätzlichen ISB.

Methoden. Retrospektiv wurden die klinischen Ergebnisse konventionellarthroskopisch behandelter Patienten ( $n=11$, Gruppe A, Partialrekonstruktion,
Bizepssehnentenotomie- oder tenodese und Débridement) und von Patienten mit zusätzlichem ISB ( $n=12$, Gruppe B) untersucht.

Prä- und postoperativ wurde die Schulterfunktion mittels Constant- und AmericanShoulder-and-Elbow-Surgeons(ASES)-Score untersucht. Nach durchschnittlich 22 Monaten füllten die Patienten einen Fragebogen zur subjektiven Patientenzufriedenheit aus. Ergebnisse. Zum Nachuntersuchungszeitpunkt wiesen beide Gruppen eine verbesserte Schulterfunktion auf (Constant-Score in Gruppe A: von 60,7 auf 77,6; $p<0,001$; Constant-Score in Gruppe B: von 36,8 auf 69,$5 ; p<0,001$ und ASES-Score in Gruppe A: von 59,1 auf 88,$6 ; p<0,001$; ASES-Score in Gruppe B: von 31,5 auf 85,7; $p<0,001$ ). Die absolute Verbesserung der Scores war für Patienten mit einem ISB höher. Beide Gruppen waren subjektiv mit dem Operationsergebnis zufrieden.

Schlussfolgerung. Der ISB stellt eine praktikable Therapieoption bei MRCT dar, die mit subjektiver Schmerzlinderung und verbesserter Schulterfunktion einhergeht. Weitere Studien mit größeren Patientenkollektiven und längerem Follow-up sind nötig, um die Sicherheit und Kosteneffizienz dieser Behandlung zu bestätigen.

Schlüsselwörter

Akromion · Schulter · Rotatorenmanschette . Débridement · Arthroskopischer Eingriff function is that the ISB was implanted particularly in patients whose major complaint was heavy pain and a poor shoulder function. The indication for an arthroscopic treatment of MRCT was probably extended since the ISB was available. In two cases, the ISB was utilized in pseudoparalytic shoulders. The affected patients still had poor shoulder function at follow-up. This finding confirms that a pseudoparalytic shoulder is a contraindication for the implantation of an ISB.

To date, the largest patient collective $(n=20)$ treated with an ISB was presented by Senekovic et al. [13]. After a 3-year follow-up they reported an improvement in the Constant score from 33.4 to 65.4 points. Pain relief was sustained for the whole follow-up period. Our patients treated with an ISB showed a similar improvement in Constant score from 36.8 to 69.5 points after 22 months. These findings indicate that even a bad preoperative shoulder function can be improved by the implantation of an ISB.

Conventionally treated patients in our study experienced a significant improvement in their affected shoulder (Constant score from 60.7 to 77.6 ; $p<0.001)$. Unfortunately, we did not assess the conventionally treated group twice. It is possible that further improvements af- 

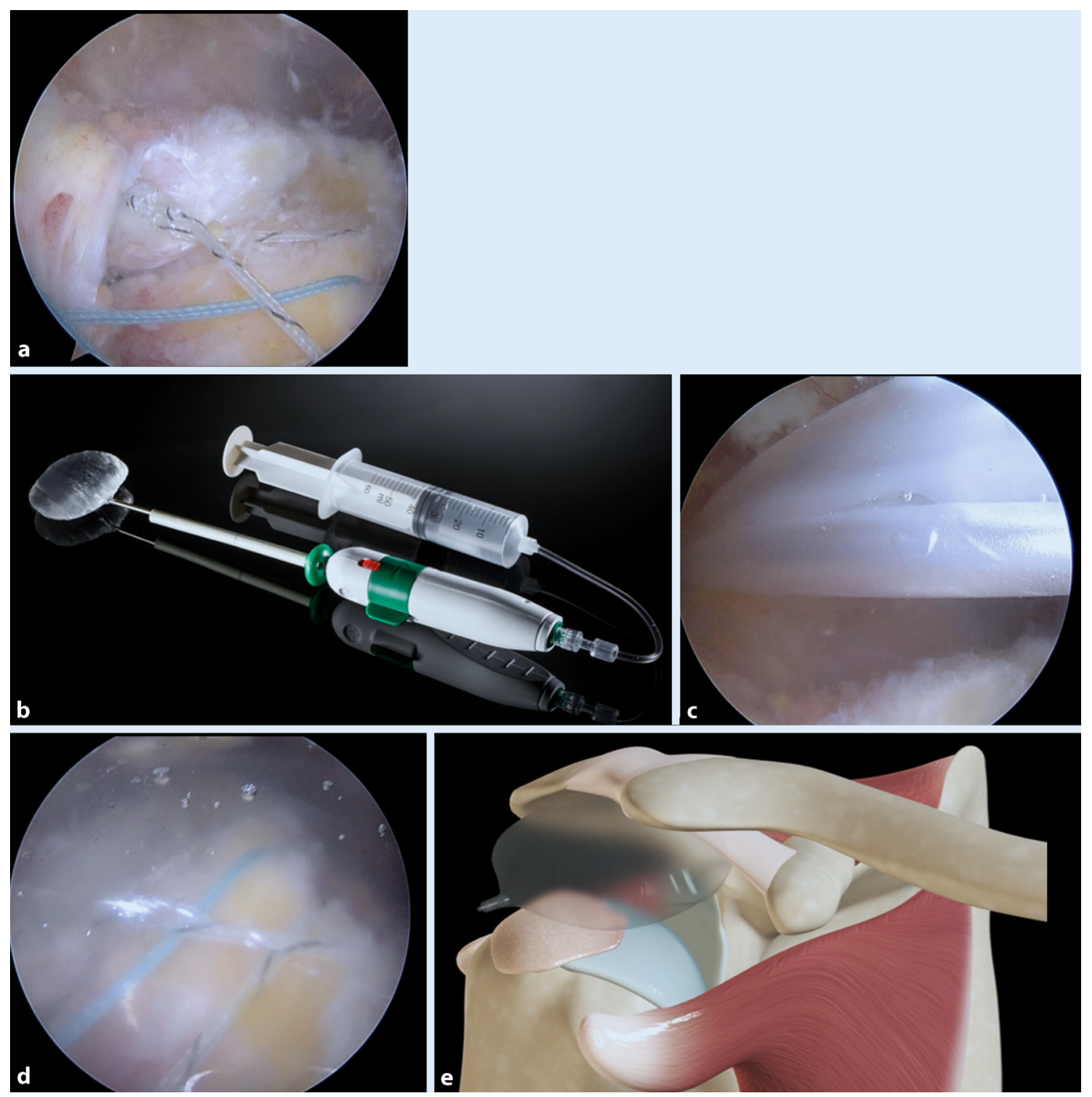

Fig. $1<$ Example of a partial reconstruction of a massive rotator cuff tear in combination with an InSpace Balloon "on top." The retracted rotator cuff tear was reconstructed with a medialized repair (a). After the reconstruction was finished, the balloon was inserted with the inflating and insertion device provided by the manufacturer $(\mathbf{b}, \mathbf{c})$ and then inflated to protect the partial reconstruction (d) and extend the subacromial space (e). (c, e Courtesy of Orthospace, Israel)

ter 11 month are a general finding for arthroscopic treatments of MRCT in the absence of pseudoparalysis. Because of the longer follow-up and the superior preoperative function of conventionally treated patients, the results cannot be compared adequately with those of patients treated with an ISB. Still, the results of both groups at final follow-up demonstrate that conventional arthroscopic techniques lead to an improved shoulder function, although the absolute improvement was higher if an additional ISB was implanted.

Porcellini et al. [10] described that partial repair of the infraspinatus tendon in combination with an intact subscapularis tendon and an irreparable supraspinatus tendon could improve the Constant score from 44 to 77 points after a minimum follow-up of 5 years. This result shows that partial repair should always be conducted, if possible. In these cases the additional implantation of an ISB may not only protect the partial repair but also improve shoulder function by supporting the force couple of the subscapularis and infraspinatus tendon. The significant improvement of clinical scores in both of our groups is probably related to the partial repairs conducted (eight in group A and four in group B). The lower number of partial repairs in group B underlines that the rotator cuff was of a poorer quality and less mobile in those patients. The ISB is probably a reason for the highly improved shoulder function although partial repair was conducted in only $33 \%$ of the patients.

The common sense that complete repairs are better than partial repairs, which are again better than a mere debridement, has been proved by Moser et al. [9] and Heuberer et al. [8]. The repair or partial repair of MRCT leads to pain reduction in over $80 \%$ of the patients $[2,5]$. Even a high rate of reversion of pseudoparalysis for repairs of MRCT in the absence of osteoarthritis has been described [4].

Since the ISB is supposed to reduce friction forces and to maintain the integrity of the repaired cuff [1], it may support the healing of the tendon-bone interface. This hypothesis could not be proven by this study and should be investigated in further studies.

An arthroscopically assisted transfer of the latissimus dorsi showed an improvement from 35.5 to 69.5 points [3]. The improvement is similar to that of our patients treated with an ISB. But of course these results cannot be compared properly because these patients were fol- 


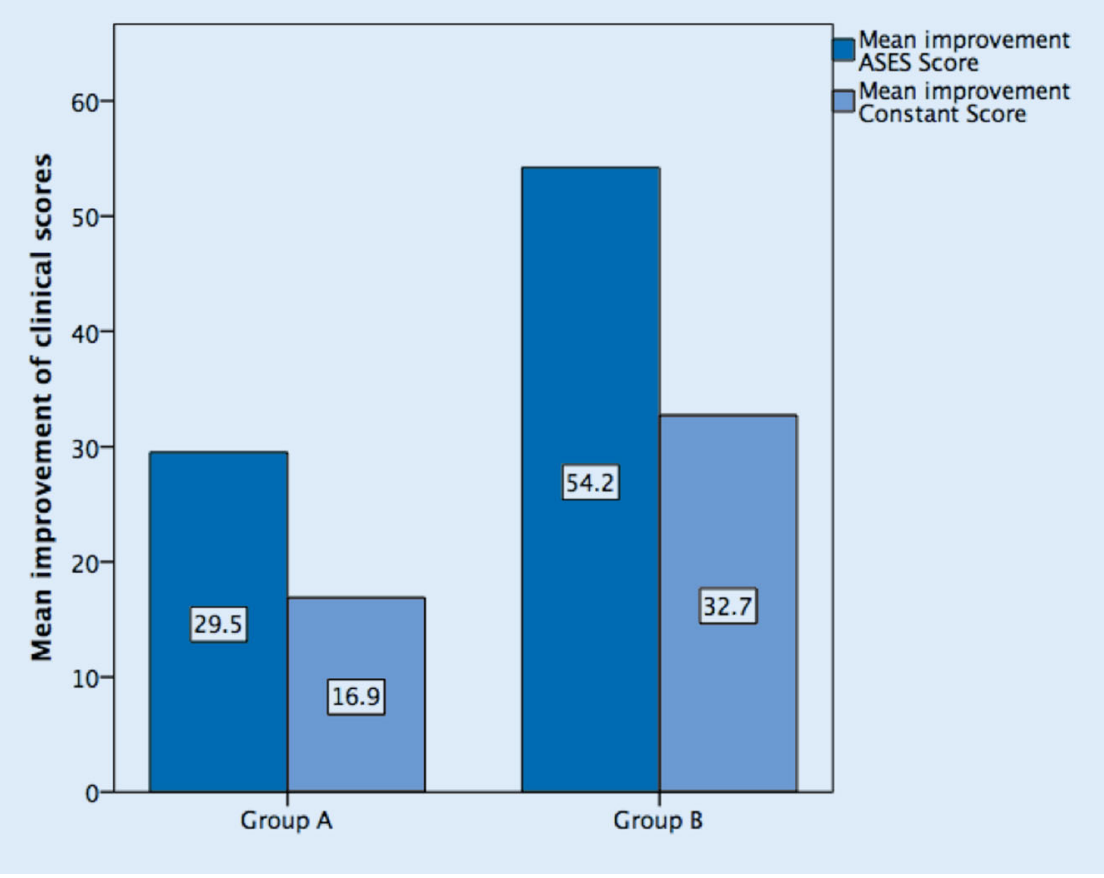

Fig. $2 \Delta$ Mean improvement of American Shoulder and Elbow Surgeons (ASES) score and Constant score for conventionally treated patients with massive rotator cuff tear (group A) and patients treated with an additional InSpace Balloon

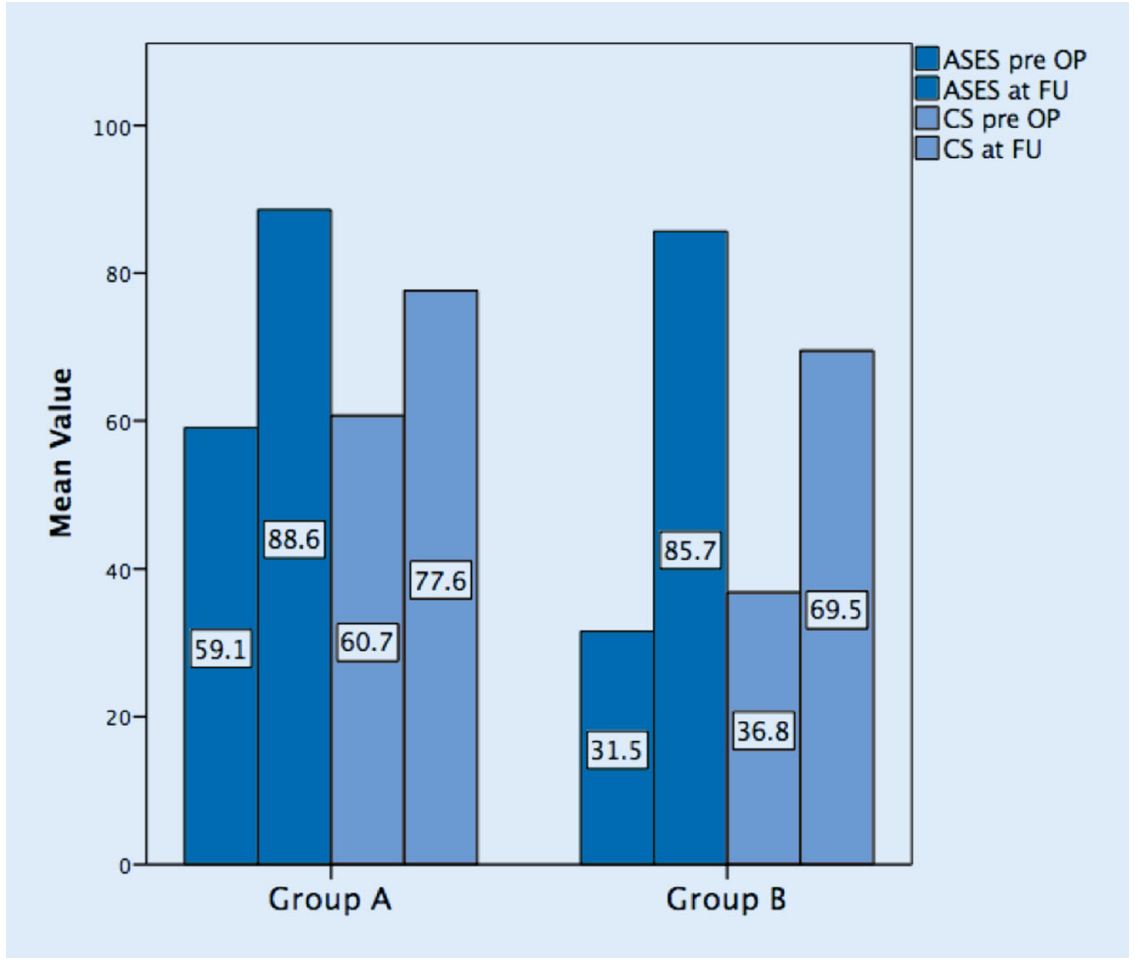

Fig. $3 \triangle$ Mean values of preoperative (pre $O P$ ) and postoperative $(F U)$ assessment of the American Shoulder and Elbow Surgeons score (ASES) and Constant score (CS) for conventionally treated patients with massive RCT (group A) and patients treated with an additional InSpace Balloon lowed up for a longer period and had a severe preoperative external rotation lag-sign. In these cases an ISB is not indicated. However, if contraindications exist for a latissimus transfer like in subscapularis tendon tears, an ISB may be an alternative treatment option.

Pain reduction has been reported [14] for the ISB, as was shown in our study with patients agreeing that their pain was reduced (Likert scale 3.3/4). Conventionally treated patients reported a similar pain relief (3.4/4); therefore we cannot state that pain reduction is a result of the ISB. It is likely that bursectomy, cuff debridement, and biceps tenodesis or tenotomy play a more important role in pain relief. One patient treated with an ISB complained of persistent pain. The symptoms could be eased with pain medication and physiotherapy. Although the MRI did not show a significant bursitis, a foreign body reaction might have played a role in these symptoms.

Although a fluoroscopy-guided implantation of the ISB under local anesthesia has been described [6], we would recommend a combination with conventional arthroscopic techniques to treat side pathologies such as bursitis, biceps tendinitis, and debridement or cuff repair. Such a short arthroscopic intervention does not require a long duration of general anesthesia in contrast to reverse total shoulder arthroplasty or complex rotator cuff repair. Therefore, the ISB should be considered if patients suffer from severe general diseases that do not allow for a long duration of surgery.

This study showed a further improvement of shoulder function between 11 and 22 months. The ISB degrades after 15 months. There is no exact explanation for this finding. We assume that a formation of scar tissue, as is presented in - Fig. 4, may play a role. Another theory why the outcome still improves after degradation of the implant is an improved muscle patterning of the force couple between the internal and external rotators, which is created by a recentering of the humeral had. Further studies need to assess the sustainability of this effect. Reduced friction forces may decrease the inflammatory component of an MRCT and consecutive bursitis and synovitis. 


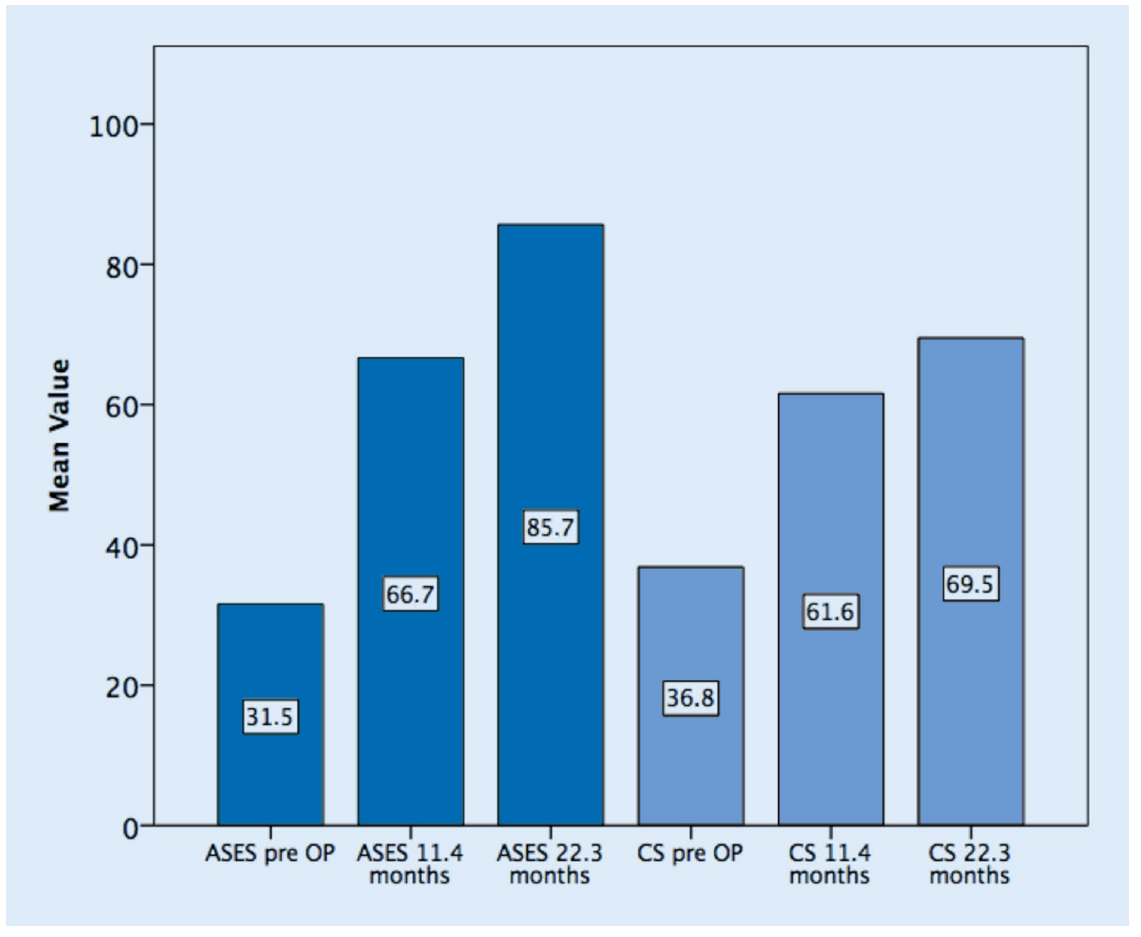

Fig. $4 \Delta$ Development of clinical results in patients treated with an InSpace Balloon. The American Shoulder and Elbow Surgeons score (ASES) and Constant score (CS) showed further improvement until the final follow-up

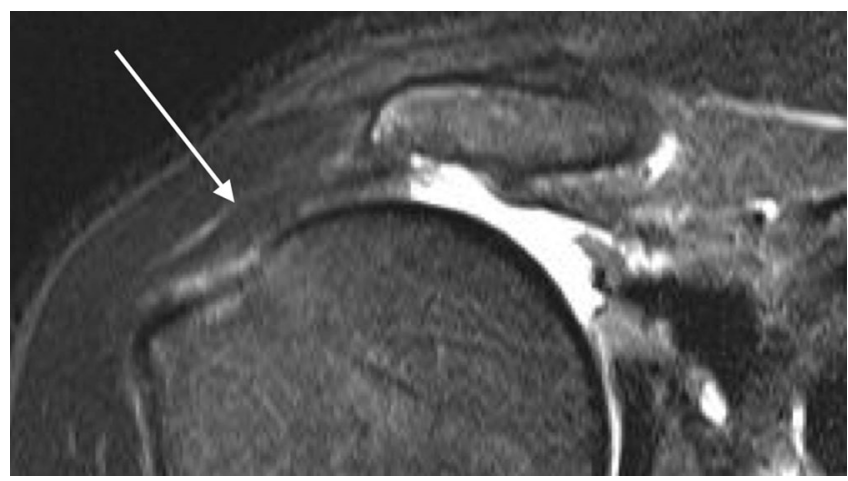

Fig. $5 \Delta$ This patient was investigated with magnetic resonance imaging (MRI) after 12 months: The MRI (T2, coronal plane) showed a deflated InSpace Balloon, which appears like a scar tissue formation in the subacromial space (white arrow)

Other arthroscopic treatment options for MRCT such as allografts, synthetic grafts, and xenografts have not yet proved to be a superior treatment option, but they should be considered as interposition scaffolds in cases of retracted tears [15]. Whether a combination with an ISB is feasible in those cases remains unclear.

Since the implantation of an ISB is not demanding compared with other arthroscopic techniques for MRCT, the surgical effort for an additional ISB is rather low, while the costs are clearly higher. This is why the implantation of an ISB

\section{Limitations}

Besides the low number of patients, this study is retrospective. The different preoperative findings and the different follow-up periods in the two groups do not allow a comparison to be made between the presented groups. The range of follow-up provides only short-term results of a heterogeneous patient collective. Furthermore, a selection bias between the two groups exists, because the ISB was implanted in patients with a significantly lower preoperative shoulder function.

\section{Conclusion}

The ISB is a feasible treatment option for MRCT, which is not difficult to perform for experienced shoulder surgeons. Beside subjective pain relief, it provides improved shoulder function, which further increases after 1 ear. While even a low preoperative shoulder function can be improved through the implantation of an ISB, a pseudoparalytic shoulder cannot be restored. Further studies with larger patient collectives and a longer followup are needed to assess whether the ISB is a safe and cost-effective minimally invasive treatment for MRCT.

\section{Corresponding address}

Dr. med M. Holschen
Raphaelsklinik Münster
Schuerbusch 55, 48143 Mün-
ster, Germany
holmal@web.de

\section{Compliance with ethical guidelines} such as a very painful shoulder in absence of pseudoparalysis and fragile partial repairs, which need to be protected by a subacromial spacer that keeps the reconstructed rotator cuff attached to the bony insertion.

Because of the low number of followed-up patients, the authors cannot recommend an uncritical use of the ISB for MRCT. Further studies with larger patient collectives need to assess midterm results and potential complications such as foreign body reactions.
Conflict of interest. M. Holschen, F. Brand, and J.D. Agneskirchner declare that they have no competing interests.

Ethical approval was given from the ethics committee of the medical faculty of the University of Hannover, Germany.

\section{References}

1. Bozkurt M, Akkaya M, Gursoy S et al (2015) Augmented fixation with biodegradable subacromial spacer after repair of massive rotator cuff tear. Arthrosc Tech 4:e471-e474 
2. Burkhart SS, Barth JR, Richards DP et al (2007) Arthroscopic repair of massive rotator cuff tears with stage 3 and 4 fatty degeneration. Arthroscopy 23:347-354

3. Castricini R, De Benedetto M, Familiari F etal (2015) Functional status and failed rotator cuff repair predict outcomes after arthroscopic-assisted latissimus dorsi transfer for irreparable massive rotator cuff tears. J Shoulder Elbow Surg 25:658

4. Denard PJ, Ladermann A, Brady PC et al (2015) Pseudoparalysis from a massive rotator cuff tear is reliably reversed with an arthroscopic rotator cuff repair in patients without preoperative glenohumeral arthritis. Am J Sports Med 43:2373-2378

5. Duralde XA, Bair B (2005) Massive rotator cufftears: the result of partial rotator cuff repair. J Shoulder Elbow Surg 14:121-127

6. Gervasi E, Cautero E, Dekel A (2014) Fluoroscopyguided implantation of subacromial "biodegradable spacer" using local anesthesia in patients with irreparable rotator cuff tear. Arthrosc Tech 3:e455-e458

7. Henry P, Wasserstein D, Park S et al (2015) Arthroscopic repair for chronic massive rotator cuff tears: a systematic review. Arthroscopy 31:2472-2480

8. HeubererPR, KolblingerR, BuchleitnerSetal (2015) Arthroscopic management of massive rotator cuff tears: an evaluation of debridement, complete and partial repair with and without force couple restoration. Knee Surg Sports Traumatol Arthrosc. doi:10.1007/s00167-015-3739-9

9. Moser M, Jablonski MV, Horodyski M et al (2007) Functional outcome of surgically treated massive rotator cuff tears: a comparison of complete repair, partial repair, and debridement. Orthopedics 30:479-482

10. Porcellini G, Castagna A, Cesari Eet al (2011) Partial repair of irreparable supraspinatus tendon tears: clinical and radiographic evaluations at long-term follow-up. JShoulderElbow Surg 20:1170-1177

11. Ramot Y, Nyska A, Markovitz E et al (2015) Longterm local and systemic safety of poly(l-lactideco-epsilon-caprolactone) after subcutaneous and intra-articular implantation in rats. Toxicol Pathol 43:1127-1140

12. Savarese E, Romeo R (2012) New solution for massive, irreparable rotator cuff tears: the subacromial "biodegradable spacer". Arthrosc Tech 1:e69-e74

13. Senekovic V, Poberaj B, Kovacic L et al (2013) Prospective clinical study of a novel biodegradable sub-acromial spacer in treatment of massive irreparable rotator cuff tears. Eur J Orthop Surg Traumatol 23:311-316

14. Szollosy G, Rosso C, Fogerty S et al (2014) Subacromial spacer placement for protection of rotator cuff repair. Arthrosc Tech 3:e605-e609

15. Thangarajah T, Pendegrass $C J$, Shahbazi $S$ et al (2015) Augmentation of rotator cuff repair with soft tissue scaffolds. Orthop J Sports Med. doi:10. $1177 / 2325967115587495$ 